\title{
Technical Basis and Programmatic \\ Requirements for Laboratory Study \\ of Hydrological Properties \\ of the Near-Field Environment
}

W. Lin

\section{Lawrence Livermore National Laboratory}

Publication Date: October 1993

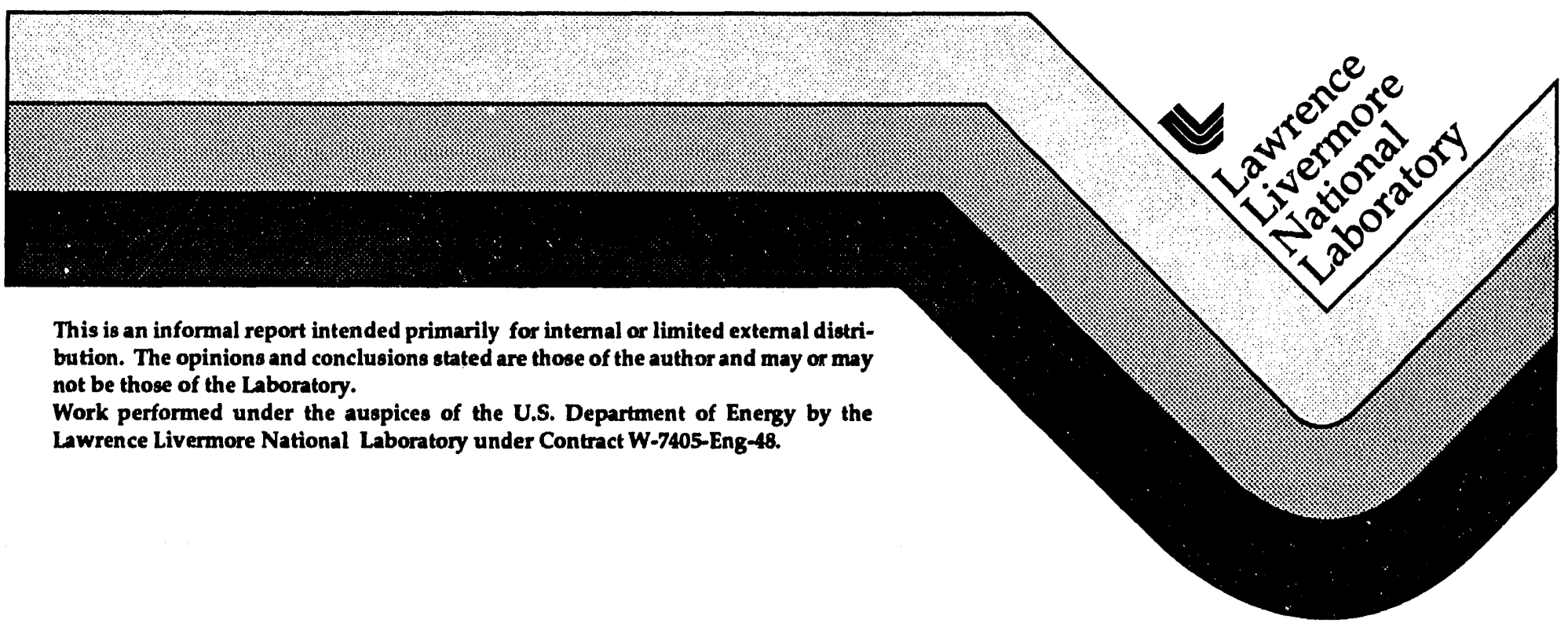




\section{DISCLAIMER}

This document was prepared as an account of work sponsored by an agency of the United States Government. Neither the United States Government nor the University of California nor any of their employees, makes any warranty, express or implied, or assumes any legal liability or responsibility for the accuracy, completeness, or usefulness of any information, apparatus, product, or process disclosed, or represents that its use would not infringe privately owned rights. Reference herein to any specific commercial products, process, or service by trade name, trademark, manufacturer, or otherwise, does not necessarily constitute or imply its endorsement, recommendation, or favoring by the Uniled States Government or the University of California. The views and opinions of authors expressed herein do not necessarily state or reflect those of the United States Government or the University of California, and shall not be used for advertising or product endorsement purposes.

This report has been reproduced directly from the best available copy.

Available to DOE and DOE contractors from the Omice of Scientific and Technical Information P.O. Box 62, Oak Ridge, TN 37831

Prices available from (615) 576-8401, FTS 626-8401

Available to the public from the National Technical Information Service

U.S. Department of Commerce 5285 Port Royal Rd. Springfield, VA 22161

Prepared by Yucca Mountain Site Characterization Project (YMP) participants as part of the Civilian Radioactive Waste Management Program. The YMP is managed by the Yucca Mountain Site Characterization Project Office of the U.S. Department of Energy, Las Vegas, Nevada. 
Technical Basis and Programmatic Requirements for Laboratory Study of Hydrological Properties of the Near-Field Environment

Wunan Lin

Lawrence Livermore National Laboratory

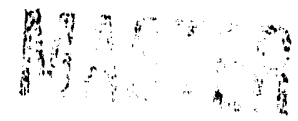


Table of Contents

1.0 Purpose and Objective

2.0 Relationships to Programmatic Objectives

2.1 Information Needs

2.2 Applicable Regulations

3.0 Background

4.0 Rationale and Justification

4.1 Rationale for Selected Studies

4.1.1 Hydrological Properties

4.1.2 Model Calibration and Validation

5.0 Activities

5.1 Activity Number GH-01, Hydrological Property Measurements

5.2 Activity Number GH-03, Model Validation Experiments

6.0 Description of Activities

6.1 Hydrological Property Measurements

6.1.1 Matrix Porosity

6.1.2 Saturated Water Permeability

6.1.3 Moisture Retention Curves

6.1.4 Klinkenberg Coefficients

6.2 Model Validation

6.2.1 Fracture Healing

6.2.2 Electric Conductivity vs. Water Content

6.2.3 One-dimensional Dehydration and Imbibition in Matrix

6.2.4 Infiltration of Water in a Fracture

6.2.5 One-dimensional Dehydration and Imbibition in Saw-cut Samples

6.2.6 Vapor Condensation in a Fracture 
6.2.7 Three-dimensional Imbibition

7.0 Application of Results

8.0 Acknowledgements

9.0 References 


\subsection{Purpose and Objective}

This document contains the technicai basis and programmatic requirements for a study plan that governs laboratory study of hydrological properies of the near-field environment of a nuclear waste repository. The Study Plan (SP), known as "NearField Environment Hydrological Properties (NFEHP)," will be reviewed by Yucca Mountain Site Characterization Project Office (YMPO) of the United States Department of Energy (DOE). The final version of the SP may be different from this document. The SP is identified by Work Breakdown Structure (WBS) as WBS 1.2.2.2.2. This study is described in Section 8.3.4.2.4.4.1 of the Site Characterization Plan (SCP). The purpose and objective of the Near-Field Environment Hydrological Properties study are to understand, at the laboratory scale, hydrological processes expected to occur within the near field of a nuclear waste repository after waste package emplacement. These processes reflect perturbations expected to be induced by the emplacement of nuclear waste packages and the subsequent effects due to heat and radiation. They will have significant effects on chemical, mineralogical, hydrological, thermal, and mechanical characteristics of the near-field environment. The characteristics of the near-field environment will affect the performance of the waste packages and the release rate of radionuclides from the near field to the far field of a repository. This study plan describes those laboratory activities that determine the hydrological properties and examines hydrological processes of the near-field environment. The laboratory experiments and tests will be used to develop, calibrate, and validate the models that will be used to simulate the processes.

The evolution of the thermal and radiation output of the waste packages will result in an environment whose characteristics may change through time. To assure that waste package design considerations account for this evolving environment, it is necessary to determine the range of conditions that may develop in the pre- 
emplacement and post-emplacement near-field environment.

The activities described in this plan have two objectives. The first is to provide input data to model calculations that are developed to understand the hydrological processes in the entire near-field environment (beyond the laboratory scale) and to characterize the environment after waste emplacement. The model calculations will be used to extrapolate our understanding of the near-field environment in both spatial and temporal domains. The second objective is to test the conceptual hydrologic processes to be used in the model calculations to contribute to the overall model validation process. 


\subsection{Relationships to Programmatic Objectives}

\subsection{Information Needs}

The Site Characterization Plan (SCP) is divided into a series of issues and information needs that address those issues. Issue 1.10 (Waste Package CharacteristicsPost-closure) deals with the service environment of the waste package. Section 8.3.4.2 of the SCP states that, "The waste package environment, upon initial emplacement of the package, will depend on the ambient conditions at the repository level and how those conditions are altered by the repository construction and operation. The environment following emplacement will depend on the initial emplacement conditions and how those conditions are altered by the waste package. Therefore, there is an interactive process between design and environment characterization. The design is initially based on the ambient conditions and a prediction of how those conditions would alter under the stresses applied by repository construction and waste emplacement. Once a design is available, analysis of that design provides a set of environmental stress factors. Testing is then done to determine the effect of those stresses, such as thermal and radiation fields and mechanical stresses, on the package environment. Based on those tests and subsequent analysis, design may be modified and the test and analysis cycle repeated."

The ability of the waste package to meet the objective of isolating nuclear wastes will depend on the interactions between the waste packages and the environment into which they are emplaced. Performance Issues 1.4 and 1.5, and their associated Information Needs (IN), address these concerns.

Issue 1.4: Will the waste package meet the performance objective for containment as required by 10 Code of Feder $₫$ l Regulations (CFR) 60.113?

IN 1.4.3: Scenarios and mode's needed to predict the rate of degradation of the containment barrier. 
IN 1.4.4: Estimates of the rates and mechanisms of container degradation in the repository environment for anticipated and unanticipated processes and events, and calculation of the failure rate of the container as a function of time.

IN 1.4.5: Determination of whether the requirement for substantially complete containment of the waste packages is met for anticipated processes and events.

Issue 1.5: Will the waste package and repository engineered barrier system meet the performance objective for limiting radionuclide release rates required by 10 CFR 60.113 ?

IN 1.5.3: Scenarios and models needed to predict the rate of radionuclide release from the waste package and engineered barrier system.

IN 1.5.4: Determination of the release rates of radionuclides from the waste package and engineered barrier system for anticipated and unanticipated events.

IN 1.5.5: Determination of the amount of the radionuclides leaving the near-field environment of the waste package.

The requirements that pertain to specific design attributes of the waste package environment are detailed under IN 1.10.1 and 1.10.4 of Issue 1.10.

Issue 1.10: Have the characteristics and configurations of the waste packages been adequately established to (a) show compliance with the post-closure design criteria of 10 CFR 60.135 , and (b) provide information for the resolution of the performance issues?

IN 1.10.1: Design information needed to comply with post-closure criteria 
from 10 CFR 60.135 (a) for consideration of the interactions between the waste package and the near-field environment.

IN 1.10.4: Post-emplacement near-field environment.

\subsection{Applicable Regulations}

The activities described in this study plan address the requirements contained in Section 135(a) of the Nuclear Regulatory Commission (NRC) rule (10CFR60) which states, in part:

"Packages for high-level waste (HLW) shall be designed so that the in situ chemical, physical, and nuclear properties of the waste package and its interactions with the emplacement environment do not compromise the function of the waste packages or the performance of the underground facility or the geologic setting." ...

"The design shall include but not be limited to consideration of the following factors: solubility, oxidation/reduction reactions, corrosion, gas generation, thermal effects, mechanical strength, mechanical stress, radiolysis, radiation damage, radionuclide retardation, leaching, fire and explosion hazards, thermal loads, and synergistic interactions." 


\subsection{Background}

The potential repository horizon at Yucca Mountain is in a devitrified, partially saturated, nonlithophysal, densely welded and fractured tuff. Work to date suggests that the potential repository horizon has a mean matrix porosity of about $11.3 \%$ (Nimick and Schwartz, 1987) and a mean water saturation of $65 \%$ (Montazer and Wilson, 1984). Therefore, the rock mass consists of host rock with pore spaces filled with air and water.

Waste package emplacement will impose thermal and radiation loads on the rock mass. The thermal load will increase the near-field temperatures and create a region of hot and dry rock around the waste package. Rapid evaporation or possible boiling of the vadose water will occur where the temperatures are sufficiently high. A buildup of pore gas pressure is expected to develop in the unfractured rock mass. Steam and vapor are expected to flow within the fractures and unfractured rock in response to the gas pressure gradients that develop. A region of increased saturation is expected to form adjacent to and outside of the dry rock region as steam condenses within the cooler portions of the rock mass. Part of this condensation will occur along fractures. Some of the condensation may move from the fractures into the matrix due to high suction potential in the matrix. The remaining water in the fracture may remain immobile due to capillary forces, or it may flow along the fracture under gravity, depending on local fracture apertures and orientations. Because the power output of the waste package decreases with time, the hot region of the rock mass eventually cools, and the dry region will slowly regain some of the water previously transported to the surrounding areas. The activities described below will provide laboratory tests of model concepts that will be used to predict the thermo-hydrological processes in the near-field rock mass after the emplacement of waste packages. They will also provide input data to the model calculations, and possibly to guide revisions in conceptual models. 
To assure that the emplacement configurations do not compromise the lifetime performance of the repository or the waste packages, their design must also consider environmental features. Processes affecting the post-emplacement environment will also influence waste package performance. The activities described below will provide input to performance assessment models for the waste package, near-field environment, and the repository.

Three broad categories of activities provide the information necessary to characterize the chemical and mineralogical, hydrological, thermal and mechanical properties that constitute the post-emplacement near-field environment. Another category of activities provides the information necessary to understand the coupled thermalmechanical-hydrological-geochemical processes in the near-field environment.

Tests, experiments, and numerical geochemical simulations described in the study plan entitled, "Characterization of Chemical and Mineralogical Changes in the PostEmplacement Environment" (WBS 1.2.2.2.1, SCP 8.3.4.2.4.1), address the category of activities that define the chemistry of water that may contact waste packages. The need for this information is specified in the issue resolution strategy for Issues 1.4 and 1.5 , where limits are placed on the quality of water that may contact the waste packages. The information gained through those activities will characterize the near-field mineralogy and chemistry. The interactions of tuff, water, water vapor, and waste package components in the presence of elevated temperature and radiation fields are considered. Those activities will establish the nature of chemical and mineralogical evolution of the waste package environment for anticipated and unanticipated conditims involving various degrees of water saturation. Another study plan entitled, "Characterization of the Effect of Man-Made Materials, Chemical and Mineralogical Changes in the Post-emplacement Environment" (WBS 1.2.2.2.5, SCP 8.3.4.2.4.1.2 and 8.3.4.2.4.1.6), addresses the category of activities that define the effect of manmade materials in a repository on the chemical and mineralogical changes. 
Tests, experiments, and numerical simulations described in the study plan entitled, "Geomechanical Attributes of the Waste Package Environment" (WBS 1.2.2.2.3, SCP 8.3.4.2.4.3), address the category of activities that establish the near-field thermal and mechanical properties of the tuff in the waste package environment. This category of activities will define the range of values of parameters that influence borehole stability and thermal response of the tuff. The study plan describes the rationale and technical attributes of activities that determine these characteristics of the waste package environment. The need for this information is specified in the issue resolution strategy for Issue 1.5 where limits are placed on the failure rate of waste containers.

The third category of activities, which are described in the present study plan, incorporates numerical model simulations, laboratory measured hydrological properties of tuff, and laboratory model validations to establish the quantity of water that may contact waste packages. This plan describes the rationale and technical attributes of activities that help determine the quantity of water that may contact the waste package. The need for this is specified in the issue resolution strategy of Issue 1.5 where limits are placed on the quantity of water that may contact waste containers. The information gained in these activities will be used to characterize the near-field hydrological properties of the tuff under anticipated and unanticipated conditions as required in Issue 1.10. These activities will define the range of values of parameters for anticipated and certain unanticipated conditions that influence fluid flow processes in the near-field environment.

Tests, experiments, and numerical simulations described in the Scientific Investigation Plan (SIP) entitled, "Large Block Testing of Coupled Thermal-mechanicalhydrological-geochemical Processes" (WBS 1.2.2.2.4, SCP 8.3.4.2.4.4), address the category of activities that investigate the coupled processes of heat, geomechanics, hydrology, and geochemistry that may occur in the rock mass in the near-field environment. These activities will investigate the mechanical responses of tuff to the thermal 
loading of the heat sources; the effect of heat and the mechanical responses of tuff on the movement of moisture around the heat sources; the chemistry of the aqueous and gas phases that may be affected by heat, the mechanical response of the rock, and the flow of vapor and liquid water. The need for this information is specified in the issue resolution strategy for Issues 1.4 and 1.5 . 


\subsection{Rationale and Justification}

The activities described in this document have been developed to provide information necessary to satisfy design and performance requirements. These requirements, which are detailed in Issues 1.4, 1.5, and 1.10, emphasize the need to estimate the water quantity that may contact waste packages. The water quantity is one of the attributes of the near-field environment that must be considered in waste package design and performance assessment.

The proposed environment in which the suitability of storing high-level radioactive waste is being investigated is a devitrified, densely welded, nonlithophysal rhyolitic tuff. To satisfy the purpose and objective of the information needs, the effects of waste package emplacement on the hydrological properties of the tuff and the hydrological transport processes in the near-field environment must be determined. To establish the nature of these effects, it is necessary to identify and characterize the processes that may influence the near-field hydrology during thermal perturbation of the environment.

The hydrological properties of the tuff are a reflection of the degree of welding, extent of secondary mineral growth, magnitude and distribution of fracturing, and degree of water saturation. The rock in the potential repository horizon has a mean matrix porosity of about $11.3 \%$ (Nimick and Schwartz, 1987) and a fracture density of between 8 and 40 fractures per cubic meter (Scott et al., 1983). The structural location of this horizon, 213 to 427 meters above the local water table (Ortiz et al., 1985), and the local meteorological conditions have resulted in a rock that is approximately $65 \%$ saturated (Montazer and Wilson, 1984). Evidence suggests that the net water flux in this unsaturated environment is 1.0 to $2.0 \mathrm{~mm} / \mathrm{yr}$ upward, although a downward flux of $1.0 \times 10^{-7}$ to $0.5 \mathrm{~mm} / \mathrm{yr}$ may occur as a result of matrix flow (Montazer and Wilson, 1984; Montazer et al., 1985). Extrapolation from Daily and Lin's (1991) data indi- 
cates that the matric potential of $65 \%$ saturated Topopah Spring tuff at $20^{\circ} \mathrm{C}$ is about $-8 \mathrm{MPa}$ during dehydration and $-3 \mathrm{MPa}$ during imbibition. At $70^{\circ} \mathrm{C}$, the matric potentials at $65 \%$ water saturation increase to $-24.5 \mathrm{MPa}$ and $-24.0 \mathrm{MPa}$ respectively. According to Wang and Narasimhan (1985), the stronger suction potential would make fracture flow less possible. However Buscheck et al. (1991) suggested that fracture flow is a strong function of the total flux, not just the suction potential of the matrix. Also, matrix flow depends on the permeability of the matrix, which is on the order of one microdarcy $\left(10^{-18} \mathrm{~m}^{2}\right.$ ) for Topopah Spring Tuff (Lin and Daily, 1984; Moore, et al, 1986). The processes that will occur upon emplacement of waste packages in the tuff and the effects of these processes on the hydrologic characteristics of the near-field must be established to meet the requirements of Information Need 1.10.4.

Characterization of the processes affecting the hydrological properties of the rock mass in the near-field environment requires knowledge of the potential fluid flow pathways under saturated and unsaturated conditions, the influence of thermal stress on fractures, the influence of fractures on fluid flow and degree of relative saturation, the relative importance of convective flow coupled with condensation and evaporation phenomena, the effect of gravity on the movement of vapor and liquid water, and dissolution and precipitation reactions that may influence pore and fracture geometry and openings and, hence, permeabilities to water and gas. The parameters that influence these processes are temperature, temperature gradient, pressure, absolute and relative permeability, suction potential and imbibition of vapor and water, and fluid chemistry. These parameters will be evaluated in model simulations, experiments, and tests.

For some scenarios under unanticipated conditions, saturation of the waste package host rock may occur. Hydrological processes under saturated conditions may differ in magnitude and nature from those that might occur under unsaturated conditions. To satisfy the requirements for resolution of Issues 1.5 and 1.10 , the hydrological processes that may occur over a range of saturation conditions must be determined. 
The temperature that the near-field environment will experience will be a function of the power output of the waste packages as a function of time and of the thermal response of the host rock. The thermal response of the host rock depends on the relative roles of conductive and convective heat transport, which, in turn, reflect interactions between water quantity and fluid flow characteristics of the near-field environment. Information obtained in the model simulation and laboratory experiments and tests will contribute to defining the thermal behavior of the near-field environment, which addresses IN 1.10.4.

\subsection{Rationale for Selected Studies}

The activities described in the following sections are designed to provide information necessary to characterize the hydrological properties and processes of the nearfield environment for anticipated and certain unanticipated conditions. Delay in this work will delay complete definition of the near-field environment needed for waste package design, waste package performance assessment, and license application. It will also delay definition of the source term to be provided for the Engineered Barrier System release rate and travel time calculations. Completion of the laboratory activities described below relies on the availability of rock materials, either as core or as blocks of rock, from the repository horizon or, for the model validation experiments, equivalent material that has the hydrological properties, such as permeability, porosity, and fracture aperture, that the principal investigator (PI) considers to be appropriate.

The determination of hydrological properties and the model validation experiments to be discussed later will increase our confidence in the thermal-hydrological models by subjecting them to various testing conditions. These experiments and measurements will also improve our understanding of the thermal hydrological processes by investigating the statical variations of the measured parameters. The relationship between the measurement and experiment activities and model calculations are 
summarized in Table 1 below. They are also included in the description of each activity in Sections 6.1 and 6.2 . 
Table 1, Relationship between Measurement/Experiment and Model Calculation Measurement-Experiment Model Calculation Hydrological Properties Input to models using hydrological codes, such as V-TOUGH and NUFT, which will extend into hydrological geochemical coupling.

Fracture Healing Experiment To determine conditions under that (Section 6.2.1) variation in fracture permeability may occur. To be used for model development. Also to validate geochemical code (e.g. EQ3-6) and test existing codes that attempt to couple hydrology and geochemistry (e.g. PRECIP and BASIN II).

1-D Dehydration-Imbibition

Experiment (Section 6.2.3

and 6.2.5), 3-D Imbibition

Experiment (Section 6.2.7)
Determine dehydration rate, imbibition rate, pore-pressure gradient; calculate relative permeability. To be used to check these parameters calculated by models using V-TOUGH code. Vapor Condensation Along Measures the amount and distribution Fractures (Section 6.2.6) of condensate along fractures. These parameters will be used to check and calibrate models using V-TOUGH and NUFT.

Infiltration in a Fracture (Section 6.2.4)
To determine fracture flow rate and imbibition rate in the matrix. These will be used to test and verify 
models using V-TOUGH codes.

Electrical Conductivity as To provide calibration databases for

a Function of Water

using electrical resistivity tomography

Saturation (Section 6.2.2) for monitoring moisture distribution

in rock that is needed for most of

the experiments in this study. 


\subsubsection{Hydrological Properties}

As mentioned in the last section, water transport within the tuff of the potential repository horizon occurs by a combination of vapor and liquid water transport through the matrix and fractures (Buscheck et al., 1991). The relative importance of each flow mechanism is a function of the bulk saturation, the amount of water transported through the rock, the temperature and temperature gradient in the rock, the fracture characteristics, and the permeability of the matrix.

The emplacement of waste packages in the rock will produce a large thermal perturbation. Buscheck and Nitao (1993) show that even with the area power density (APD) of the SCP case the temperature after 557 years of emplacement of 30-year old spent fuel will be above the boiling point of water within a region $90 \mathrm{~m}$ above and 60 $\mathrm{m}$ below the repository horizon. This thermal lo, , in turn, will cause water to vaporize and migrate in the near-field and will result in an altered hydrologic regime. Because liquid water is the main corrosive medium for the metal container and the main agent for the dissolution and transport of radionuclides, laboratory and numerical modeling studies are necessary to characterize the flow of water in the Topopah Spring tuff.

Numerical modeling studies of the flow of water in the Topopah Spring tuff, using V-TOUGH and NUFT codes, require hydrological properties of the host rock matrix and fracture as input data. The required hydrological properties include saturated water permeability, gas and liquid permeabilities as functions of water saturation and temperature, suction potential as functions of saturation and temperature for drying and wetting, porosity, and Klinkenberg coefficients for Knudsen diffusion. These properties will be determined on tuff samples from the repository horizon.

Due to inevitable limitation of resource and time, the number of measurement of these hydrological properties will be determined by the PI. The number of measure- 
ment will depend on the consistency among the measured results in each rock type and the uniformity of the rock mass at the potential repository horizon. Some of the properties, such as effective porosity and water permeability, will be determined on all samples that we study. Klinkenberg coefficient can be estimated from liquid permeability (Heid, et al, 1950). We may determine Klinkenberg coefficient in a few samples of Topopah Spring tuff to confirm the relationship between Klinkenberg coefficient and water permeability. 


\subsubsection{Model Calibration and Validation}

Numerical modeling using V-TOUGH and NUFT codes will be used to understand and predict the hydrological processes in the near-field of the repository as a function of time and space after the emplacement of the waste packages. Calibration and validation of the model are essential so that the numerical prediction of the hydrological characteristics of the near-field environment can be used for the waste package design and the assessment of the performance of the waste package and the repository.

Because the potential repository horizon is only partially saturated with water, an interconnected gas phase may be assumed to exist initially at local atmospheric pressure. As the rock mass heats following waste emplacement, pore water will begin to evaporate and gas pressure will increase. This phase change and the low gas permeability of the matrix relative to the fractures will induce a significant gas-phase pressure gradient between the matrix and the fracture system. The pressure gradient will result in migration of the vapor phase from the matrix into the fracture system and away from the waste package. As heating progresses, a local pressure gradient may exist between the matrix in the drying-out region and fractures in the dried region. This pressure gradient may cause vapor/steam to flow toward the waste package, especially if the fracture intersects the waste package borehole or drift. Therefore the dehydration of the near-field region will depend on the distribution and configuration of fractures.

The flow of vapor/steam in the fractures away from the waste packages will result in condensation along the fracture walls in the cooler region. Whether the liquid condensation along the fracture wall will attain water saturations sufficient to result in liquid phase mobility within the fracture, or whether condensate will imbibe into the rock matrix as rapidly as it forms, must be established. The answer to this question depends on the rate of condensation, capillary suction gradient, liquid phase permeability in the matrix and fractures, and the effects that secondary minerals along fracture 
surfaces have on the imbibition of water. Laboratory results indicate that imbibition of water into the tuff during the flow of vapor is much slower than when the vapor is condensed into liquid water (Lin, 1992). Model predictions of the amount and distribution of vapor condensation in a fracture needs to be validated. Laboratory tests on heated blocks with known fracture patterns to determine the distribution of water and temperature are needed to validate numerical model predictions.

The size of the dried-out region around the waste package is inversely dependent on the efficiency of the primary mechanism of heat transfer. When liquid phase is mobile in the fractures, a highly efficient vapor-liquid counter flow, or "heat pipe", system may be established (Preuss et al., 1984), which may result in a smaller driedout zone around the waste package. If heat conduction is the dominant heat transfer mechanism, a far less efficient vapor-liquid counter flow system may develop, potentially resulting in a larger dried-out zone (Buscheck, et al, 1993). Fractures approximately parallel to the thermal and hydraulic gradients could further interfere with the vapor-liquid flow system. Within the dehydration zone around the waste package, the only available mechanism of heat transfer is heat conduction, which is far less efficient than the vapor-liquid counter flow "heat pipe" system. Examination of these effects is necessary to develop a model characterizing the hydrologic properties of the near-field.

Laboratory-determined dehydration and imbibition as functions of time and space are necessary to calibrate the numerical model that will be used to characterize the movement of vapor and liquid water in the near-field of waste packages. Lin and Daily (1989 and 1990) and Lin (1991) have reported that flowing liquid water or steam in fractured Topopah Spring tuff samples at temperatures greater than $90^{\circ} \mathrm{C}$ may cause fractures to heal, resulting in a drastic decrease in permeability. However, Lee and Ueng (1991) reported an increase in air permeability in the heater borehole after heating the rock mass to about $240^{\circ} \mathrm{C}$ in a field test in G-Tunnel, Nevada Test Site. Laboratory experiments will be conducted to investigate this apparent contradiction. 
We will investigate the effect of confining pressure and the amount of water flows through a fractured sample on the fracture healing. In general the effect of moisture movement on the hydrological properties of the fractured rock mass in the near-field environment must be determined to develop a numerical model that can properly characterize the hydrological processes in the near field. The reported fracture healing was attributed to dissolution and deposition of minerals along fracture surfaces by hot water or vapor flowing through the sample. Apparently, rock-water interaction will happen in the near field of a nuclear waste repository. The effect of hydrological processes on geochemistry, and vice versa, need to be established. The laboratory result on the rock-water irteraction and the coupling between geochemistry and hydrology can be used to validate geochemical code, such as EQ3/6, and to develop codes that attempt to model the coupled hydrological-geochemical process, such as PRECIP and BASIN II.

The thermal output of the waste package will diminish through time. Temperature in the rock mass will decrease, and the water that has been driven away by the heat will re-wet the dry-out zone through matrix imbibition and liquid flow in fractures. In addition, unanticipated events, such as greater episodic infiltration due to climatic change, could result in scenarios in which rapid flow of water in the vicinity of waste packages could episodically rehydrate previously dehydrated host rock. Repeated dehydration/rehydration cycles may thus be a part of some unanticipated scenarios. The effect of such events must be evaluated to satisfy Issue 1.10. Laboratory study of the movement of a water front from a three-dimensional imbibition process will be needed to validate a numerical model that is geared to understand the rehydration process. Laboratory study of the infiltration of water into a fracture and how the water is imbibed by the matrix is needed for model validation. 


\subsection{Activities}

Work performed in support of the Near-Field Environment Hydrological Property determation has been divided into the following activities for quality assurance level grading.

\subsection{Activity Number GH-01, Hydrological Property Measurements}

To determine the hydrological properties of repository horizon Topopah Spring tuff (which is divtrified, densely welded, nonlithophysal tuff) samples. The hydrological properties include effective porosity, water permeability, gas permeability, suction potentjal, and Klinkenberg coefficient (for calculating Knudsen diffusion coefficient of water vapor).

\subsection{Activity Number GH-03, Model Validation Experiments}

To conduct experiments to test and calibrate thermo-hydrological processes used in model calculations. The experiments include fracture healing, one-dimensional dehydration and imbibition, electrical conductivity vs. water content, fracture flow and matrix flow, vapor condensation in a fracture, and three-dimensional imbibition. 


\subsection{Description of Activities}

\subsection{Hydrological Properties Measurements}

Hydrological properties of rock samples from the repository horizon or equivalent materials will be determined. The tuff to be used in the experiments described in this Section is the repository horizon Topopah Spring tuff that is divitrified, densely welded, and nonlithophysal. These properties will be used as input data to numerical model analysis and to characterize the samples used in model calibration and validation experiments. The hydrological properties to be determined include saturated water permeability, suction potential as a function of water saturation for drying and wetting (moisture retention curves), matrix porosity, and Klinkenberg coefficient for Knudsen diffusion. The moisture retention curves and the imbibition history of water in tuff will be used to solve the inverse problem of Richard's equation for relative permeability, which is an essential parameter in understanding the flow of both gas and liquid in an unsaturated medium.

Methods to determine these hydrologic properties are described below. PI will have the flexibility of using other methods of their choice to determine these properties. As mentioned in Section 4.1.1, PI will also have the flexibility of determining the number of measurements to be performed on certain properties, based on the variability of the measured results. Modification of the experimental method and/or adding new method of determining these hydrological properties will be documented in scientific notebooks and, if necessary, in the revised version of this study plan.

\subsubsection{Effective Matrix Porosity}

A sample without visible fractures will be used for the determination of effective matrix porosity. The sample material will be machined into an appropriately sized cylinder. The accuracy of the dimensions of the sample should be better than $0.5 \%$. 
The sample volume is calculated from its dimensions. The sample will be dried in a vacuum oven at temperatures low enough to prevent any alteration in mineralogy or thermal cracking. Normally, temperatures below $35^{\circ} \mathrm{C}$ will be used. The sample will be weighed periodically to monitor the decrease of sample weight due to drying. The sample is considered dried when its weight remains unchanged for at least one day. The dry density of the sample is calculated by dividing the dry weight of the sample by its volume.

We will also dry samples in a humidity chamber at low humidity levels, such as $20 \%$ relative humidity. The dry density of a sample determined using a vacuum oven at low temperature will be compared with that determined in a low humidity environment.

The dry sample is then saturated with water. To do this, the sample is placed under vacuum, and then water is allowed to flood and cover the sample. The sample is left in water and placed under vacuum again. The weight of the sample is measured periodically. The sample is considered saturated when its weight remains unchanged for at least one day (initial steady state). We usually keep the sample in water for several days after the initial steady state. Our experience indicates that the weight change after the initial steady state does not contribute to the uncertainty of effective porosity greater than the desired accuracy. The saturated density of the sample is calculated by dividing the saturated weight of the sample by its volume. The effective matrix porosity of the sample is the difference between its saturated density and dry density, divided by the density of water. The effective matrix porosity determined by this method is considered to be relevant for studying the transport of water.

Measurement Uncertainty-

The accuracy of the determined effective porosity should be within about $1 \%$. The largest source of uncertainty is in determining the volume of the sample in which a $1 \%$ accuracy must be obtainable. 
Range of Expected Results-

The tuff samples we will work on is the densely welded nonlithophysal Topopah Spring tuff. There is very little pumice in the rock. The RIB (1992) reports the expected value of the effective matrix porosity of the welded Topopah Spring Tuff (TSw2) is between 8.5 and $15.7 \%$. A welded tuff sample from the Topopah member (hole USW G-1 at $376 \mathrm{~m}$ depth) was found, using mercury porosimitry, to have a porosity of $6.54 \%$ (K. G. Knauss, private communication, 1986).

\subsubsection{Saturated Water Permeability}

A steady state flow-through method will be used to measure the saturated water permeability. Further details of the procedures are contained in Lin and Daily (1984) and Daily and Lin (1985).

Fractured and intact cylindrical samples are saturated with water. The saturation procedures are the same as described in Section 6.1.1. The saturated sample is jacketed and placed in a pressure vessel. The sample is brought to the desired confining pressure, pore pressure, and temperature. A small pore-pressure gradient is created across the longitudinal axis of the sample so that the pore fluid flows at a measurable rate. The measured steady state flow rate of the pore fluid and the pore-pressure gradient will be used, along with the cross sectional area of the sample and the viscosity of the pore fluid (which may be obtained from a handbook of physical properties of water) to calculate permeability, using Darcy's law:

$\mathrm{k}=\mathrm{qv} \mathrm{l} /(\mathrm{Ap})$

where $\mathrm{q}$ is volumetric flow rate in $\mathrm{cm}^{3}$ per second

$v$ is viscosity of water in centipoise

1 is the sample length in $\mathrm{cm}$

A is the cross section area of the sample in $\mathrm{cm}^{2}$

$\mathrm{p}$ is the pore-pressure difference across the sample in atm 
$\mathrm{k}$ is permeability in darcy.

The water that flows through the sample will be collected and analyzed for the primary constituents of the rock and water to evaluate the rock-water interaction process. Analysis for the elements $\mathrm{Si}, \mathrm{Al}, \mathrm{Ca}, \mathrm{Na}, \mathrm{K}, \mathrm{Mg}, \dot{\mathrm{Fe}}$, and $\mathrm{B}$ is done by inductively coupled plasma atomic emission spectroscopy (ICP). This technique is used because it provides reproducible, high-precision $( \pm 10 \%$ for all elements except $\mathrm{K}$, which is $\pm 20 \%$ ) results on small volume (5 milliliters) samples. High accuracy in the sub-parts per million range is obtainable with the ICP for most of the elements of interest. Atomic absorption spectroscopy (AA) is used as a supplementary means for obtaining $\mathrm{K}$ analyses in the $\pm 10 \%$ range. Ion chromatography (IC) is used to obtain analyses for the anions $\mathrm{F}^{-}, \mathrm{Cl}^{-}, \mathrm{NO}_{3}^{-}$, and $\mathrm{SO}_{4}^{-}$. Alkalinity, primarily in the form of bicarbonate $\left(\mathrm{HCO}_{3}^{-}\right)$, is determined using an automated total alkalinity titration technique. AA, IC, and alkalinity titration provide analyses of high precision and accuracy $( \pm 10 \%)$ in the parts per million range, which covers the concentration range for species of interest in these solutions and which provides the accuracy necessary for determining reaction processes.

\section{Measurement Uncertainty-}

The main uncertainty in the measured permeability is in the determination of the pore-pressure gradient and the volumetric flow rate. For low permeability (on the order of one microdarcy), the uncertainty is about 20 to $50 \%$ of the determined permeability. For greater permeability, the uncertainty is about 10 to $20 \%$. The required tolerance of the permeability measurement should be determined by the sensitivity analysis of model studies.

\section{Range of Expected Results-}

The expected range of saturated water permeability of intact welded Topopah Spring tuff is between 0.1 and $10 \mu \mathrm{d}$. The saturated water permeability of non-welded 
intact tuff is on the order of one millidarcy. Previous studies suggest that the saturated water permeability of an intact welded tuff sample does not change with increasing temperature (Lin and Daily, 1984). The saturated water permeability of a fractured sample depends on the fracture apertures and the number of fractures in the test sample. With an axially oriented single fracture of less than $0.1 \mathrm{~mm}$ apparent aperture, the expected permeability is on the order of one millidarcy. Previous studies suggest that permeability of fractured samples decreases with increasing lemperature (Lin and Daily, 1984; Daily, et al, 1987).

\subsubsection{Moisture Retention Curves}

The matric potential will be determined by measuring relative humidity in equilibrium with a sample at fixed temperatures. For the imbibition of water in tuff, the suction potential is almost equal to the matric potential. The degree of saturation will be determined by comparing the sample weight with its dry weight and saturated weight. Various degrees of saturation are achieved by equilibrating samples with known relative humidities or adding a known amount of water to the sample. Repeating these measurements over a range of saturations allows determination of the curve that defines the variation of suction potential with degree of saturation (moisture retention curve) at each fixed temperature. The measurements will be repeated for other temperatures. Matric potential is defined by Kelvin's law as

$P_{s}=\rho \mathrm{RT} \log _{e}\left(\mathrm{e} / e_{0}\right) / \mathrm{M}$

where $P_{s}=$ matric potential, in $\mathrm{MPa}$

$\rho=$ density of water $\left(\mathrm{gm} / \mathrm{cm}^{3}\right)$ at the temperature of interest

$\mathrm{R}=$ Universal gas constant $\left(8.31\right.$ Joules $/{ }^{\rho} \mathrm{K}$-mole $)$

$\mathrm{T}=$ Temperature $\left({ }^{\circ} \mathrm{K}\right)$

$\mathrm{M}=$ molecular weight of water $(18 \mathrm{gm} / \mathrm{mole})$

$\mathrm{e} / e_{0}=$ relative humidity . 
To determine the moisture retention curve of rock samples in vapor, we will use a constant humidity chamber. For the wetting phase, a dry sample is placed in a constant humidity chamber. The chamber is brought to the desired temperature and relative humidity. The sample is then weighed periodically to determine when it has reached an equilibrium weight. The relative humidity is used to calculate the matric potential, and the total weight change allows computation of the degree of saturation. The measurement is repeated at higher humidities, at the same temperature, until the maximum relative humidity in the chamber is reached, which is about $98 \%$. The measurement process is then reversed to measure the matric potential in a drying phase. The cycle of measurement is then started again at another temperature. The highest level of saturation that can be attained in a sample using this method is about $30 \%$ of its pore volume ( $\operatorname{Lin}, 1992$ ). This may be because the saturation process was started from a dry sample. We will also try other procedures: start with a water saturated sample to complete the measurements in a drying phase until the saturation level is irreducible in a constant humidity chamber, then start the measurements in the wetting phase. The two methods of drying a sample, in a vacuum oven at nearambient temperature and at low humidity level in a humidity chamber, will be compared to evaulate their effect on drying the Topopah Spring tuff samples.

To determine the moisture retention curve of rock samples at higher levels of water saturation, we will measure relative humidity in a sealed rock sample and change the saturation level by adding water to the sample or drying the sample. The saturation level of the sample is determined by weighing it, as described in the previous paragraph. The device for measuring relative humidity in a sample can be a chilled-mirror psychrometer (Flint, et al, 1992) or resonant cavity. A Chilled-mirror psychrometer is limited to near-ambient temperature application and a range of suction potentials from -10 to $-3 \times 10^{4} \mathrm{~m}$ of water head $\left(-1\right.$ to $-3 \times 10^{3}$ atm). A resonant cavity does not have these limitations. 
Both methods of measuring moisture retention curves allow the determination of hysteresis between drying and wetting conditions. The effect of drying and wetting on the hydrological properties of the sample, especially at elevated temperatures, must be assessed. To determine this effect, some of the samples with similar moisture retention curves at room temperature will be divided into three groups. The samples in one of the three groups will be subjected to a complete drying and wetting cycle at high temperature; samples in the other two groups will be subjected to either drying or wetting phase only. Then the results from these three groups will be compared to determine the effect of drying and wetting at high temperature on the moisture retention curve.

Range of Expected Results-

Based on the data obtained at room temperature reported by Klavetter and Peters (1987) and the room-temperature and high-temperature results reported by Daily and Lin (1991), the expected range in suction potential is from 0 to $10^{4} \mathrm{~atm}$, when the sample is between saturated and dry conditions respectively.

Measurement Uncertainty-

Two measurements are involved in the determination of moisture retention curves: weight and relative humidity. The accuracy of determining the weight of a sample is better than $0.01 \%$. The high-temperature constant humidity chamber can maintain a humidity level within $\pm 2 \%$ relative humidity of a set value. The accuracy of the humidity measurement is about 2 to $5 \%$. The corresponding uncertainty in matric potential is about $45 \%$ at $95 \%$ relative humidity ( a matric potential of $7 \mathrm{MPa}$ ) and about 5 to $7 \%$ at $40 \%$ relative humidity (a matric potential of $123 \mathrm{MPa}$ ).

\subsubsection{Klinkenberg Coefficient}

The Klinkenberg coefficient will be used to calculate the Knudsen diffusion coefficient of gas. The Klinkenberg coefficient as a function of temperature beyond 
the boiling point of water will be determined. In the matrix part of a rock mass Knudsen diffusion may exist at temperatures greater than the boiling point of water, dependent upon the pore pressure. As mentioned in Section 4.1.1, the Klinkenberg coefficient at room temperature will be determined in a few Topopah Spring tuff samples to confirm the relationship between Klinkenberg coefficient and liquid permeability suggested by Heid, et al (1950). The effect of temperature on gas permeability in the tuff will be measured to determine whether the correlation can be extended to greater temperatures. The method of determining the Klinkenberg coefficient is described by Reda (1987). Basically, gas permeability in a dry intact tuff sample will be measured at various levels of pore fluid pressure, while the effective pressure on the sample (effective pressure $=$ confining pressure - pore fluid pressure) is maintained constant. The slope of a plot of the gas permeability vs. the inverse of the pore-fluid pressure is the product of the Klinkenberg coefficient and the saturated water permeability of the sample. Therefore, the saturated water permeability of the sample should be determined first. The water permeability can be determined following the procedures described in Section 6.1.2. The effective porosity of the sample will also be determined, following the procedures described in Section 6.1.1. Because dry sample is used, we do not expect that the water saturated permeability and the effective porosity of samples will change due to the measurement of gas permeability. However, they will be determined again after the measurement of the Klinkenberg coefficient.

The procedures for measuring gas permeability are basically the same as measuring water permeability (Section 6.1.2). The sample for the gas permeability measurement must be dried before jacketing. The sample will be dried in a vacuum oven at a temperature no higher than $35^{\circ} \mathrm{C}$ until its weight remains unchanged for at least one day. The dry sample is then jacketed and put in a pressure vessel to be saturated with dry gas (usually $N_{2}$ ) at a certain level of pore pressure. Then the permeability is measured using the steady-state flow rate method. 
We will also measure the gas permeability in a sample with residual water saturation, instead of dried in a vacuum oven. We will dry a sample in a humidity chamber. The saturation level will be determined as a function of decreasing relative humidity. The sample will be considered to contain residual water when its saturation can not be significantly reduced. Klinkenberg coefficient will be determined in such a sample. We have to make sure that the sample does not dry out during the measurement. Semi-permeable membrane that only allows gas to pass may be used to help keeping the sample from drying out. The sample will be weighed before and after testing to check its saturation condition.

Range of Expected Results-

The measured gas permeability depends on the pore-fluid pressure. According to Reda (1987), the gas permeability may be as high as ten times the water permeability. Therefore the gas permeability of intact, densely welded Topopah Spring tuff is in the range of several microdarcies to hundreds of microdarcies. There are not enough data to establish an expected range of value of the Klinkenberg coefficient. One measurement by Reda (1987) shows that the Klinkenberg coefficient of densely welded tuff is about $0.76 \mathrm{MPa}$.

\section{Measurement Uncertainty-}

The accuracy of the gas permeability measurement is about the same as that of the water permeability measurement, in the range of 10 to $15 \%$. The accuracy of the poie-pressure measurement is about $1 \%$. The accuracy of the calculated Klinkenberg coefficient is difficult to assess, because it involves curve fitting and calculation of slope. With good data, i.e., good linear relation between permeability and inverse pore pressure, we may expect the uncertainty to be about $20 \%$. The acceptable uncertainty of the calculated Klinkenberg coefficient should be determined by a sensitivity analysis model studies. 


\subsection{Model Validation}

Model calculations are used to predict the movement of moisture in a repository for tens of thousands of years based on the results of laboratory and field measurements on a finite number of samples and locations in a relatively short period of time (several years at most). The model takes into consideration the effect of evaporation and boiling of water caused by heating of the waste packages. In the model calculations, the effect of fractures on the transport of water, steam, vapor, and heat is also considered. The thermo-hydrological processes used in the model calculations should be validated by laboratory experiments under controlled conditions and by field tests. The laboratory calibration and validation experiments are described below.

The experiments described below are for general planning purpose only. Detailed experimental procedures will be included in Activity Plan(s). Scoping calculations will be done to help determine the experimental requirements, error analysis, etc. Experimental design and procedures may be changed to reflect the evolving understanding of the thermal-hydrological processes in a nuclear waste repository. New experiments will be added if deemed necessary by the PI. All modification of the initially planned experiments and initiation of new experiment will be documented in scientific notebooks and, if necessary, in the revised version of this study plan.

\subsubsection{Fracture Healing}

It has been observed in the laboratory that flowing water at temperatures greater than $90^{\circ} \mathrm{C}$ through a fractured Topopah Spring tuff sample causes a drastic decrease in permeability (Lin and Daily, 1984; Daily et al., 1987; Lin and Daily, 1989; Lin and Daily, 1990). Lin (1991) reported that flowing (probably) wet steam through a naturally fractured tuff sample at a temperature of $127^{\circ} \mathrm{C}$ decreases $N_{2}$ permeability. The fracture healing was observed in samples with a natural fracture, an induced tensile fracture, and a saw cut (Lin and Daily, 1989). They also showed that $N_{2}$ permeability in a dry tuff sample at the same confining pressure was not affected by temperature. 
However, Lee and Ueng (1991) reported an increase in gas permeability in the heater hole of the field test in G-Tunnel, Nevada Test Site. In the laboratory experiments, the sample was under a constant confining pressure of $5 \mathrm{MPa}$. The confining pressure is probably one of the major factors influencing the laboratory results. Another factor that may affect fracture healing is the amount of water or steam flowed through a sample before the fracture begins to heal. In this experiment, the fracture healing will be studied at various confining pressures, and the amount of pore fluid that flows through the sample will be measured. Water flowed through the sample will be analyzed for chemical changes; the fracture surfaces will be examined before and after the experiment for mineralogical changes. Results of this experiment will be used in development of thermal-hydrological model, using V-TOUGH and NUFT codes, that will take variable hydrological properties, such as permeability and fracture aperture, into consideration. The results will also be used to validate geochemical model using EQ3/6 and to develop thermal-hydrological-geochemical coupling codes (e.g. PRECIP and BASIN II).

Naturally fractured cylindrical samples of the tuff or equivalent material of at least $2.5 \mathrm{~cm}$ diameter and $10 \mathrm{~cm}$ length will be used. The samples will be saturated with J-13 water or appropriate fluid as determined by the PI, and then jacketed in a soft jacket that has an operational temperature rating of at least $150^{\circ} \mathrm{C}$. The pore fluid pressure should be greater than the steam pressure at the testing temperature so that the pore water will remain in liquid form, which is about $0.5 \mathrm{MPa}$ at $150^{\circ} \mathrm{C}$. Saturated water permeability will be measured at a confining pressure of just a few tenths of $\mathrm{MPa}$ greater than the pore fluid pressure, and the testing temperatures will be varied from room temperature to at least $150^{\circ} \mathrm{C}$ and returned to room temperature. The amount of water flows through the sample in each permeability measurement will be kept at minimal. If no decrease in permeability is observed, the experiment will be repeated with the same sample at a slightly greater confining pressure, but, with the 
same pore pressure. Thus, the influence of effective pressure on fracture healing will be determined. If fracture healing is observed for the lowest confining pressure case, then an experiment at room pressure and elevated temperatures will be conducted. In this case, the sample will be sealed with adhesive material, and water will be flowed through the sample by gravity force only. Temperature will be kept below the boiling point of water.

Another experiment will be conducted to test the effect of amount of water flows through the sample on fracture healing. The same experimental procedures described in last paragraph will be conducted on a new fractured sample at a confining pressure less than that fracture healing occurs, as determined in last experiment, and at a high temperature, bewteen 95 and $150^{\circ} \mathrm{C}$. Water permeability will be determined as a function of the amount of water flowed through the sample.

We also plan to conduct an experiment that the water is recycled through the same sample in both situations that fracture healing occurs and does not occur. This experiment will test the effect of refluxing water on fracture healing. It will also provide information on the geochemical processes related to refluxing.

The water that flows through the sample during the fracture healing experiment will be collected and analyzed so that the quantity can be determined, and its chemical composition can be compared with that of the virgin water. Scanning electronic microscope (SEM), microprobe analysis of elements, and fracture surfrice image analysis will be done on the fracture surfaces of the test sample (post-experiment) and a piece of the surface adjacent to that being tested for fracture healing (pre-experiment) to examine mineralogical changes associated with fracture healing. These tests will provide information on the geochemical processes, including rock-water interaction, mineralogical changes, and cation exchange capacity of the minerals, that may be associated with fracture healing.

\subsubsection{Electrical Conductivity vs. Water Content}


In most of the experiments that we will do to validate the thermo-hydrological model, the spatial and temporal distributions of moisture in a test sample will be determined. Measurements of electrical conductivity, such as two-electrode measurement and impedance imaging, are among the methods that will be used to determine the spatial and temporal distribution of moisture in a sample. In order to obtain quantitative measurements of the moisture distribution, a relationship between the measured electrical conductivity and water content will be established. The purpose of this activity is to determine the almost-DC electrical conductivity of testing material at various degrees of water content for both draining and imbibition conditions at various temperatures.

In addition to water content, conduction of electrical current in rock may also be affected by cation exchange between minerals. Although cation exchange is not expected to have significant effect on electrical conductivity of this Topopah Spring tuff, we will determine the cation exchange capacity of the samples used in this activity, using the method explained in Section 6.2.1. The equation by Waxman and Smits (1968) will be used to evaluate the effect of cation exchange on the measured electrical conductivity.

Samples will be machined to disks approximately $5 \mathrm{~cm}$ in diameter with four thicknesses: approximately $1 \mathrm{~mm}, 2 \mathrm{~mm}, 3 \mathrm{~mm}$, and $4 \mathrm{~mm}$. Ten samples of each thickness will be measured. Effective porosity of these disk samples will be determined, following the procedures described in Section 6.1.1. The rock core adjacent to these disk samples will be used for determining saturated water permeability, as described in Section 6.1.2, cation exchange capacity, mineralogy, and pore size distribution. Platinum or gold electrodes will be vapor deposited on the flat surfaces of each sample. The two-terminal electrical resistance of each sample will be measured at various degrees of water content. The electrical conductivity of the water is determined by a commercial grade conductance probe. Enough time between each change 
of water content is allowed for the water to be uniformly distributed in the sample. The measured electrical conductivity as a function of time will be used to determine whether the sample has reached equilibrium or not. The measurements are repeated so that a complete cycle of drying and imbibition is covered.

The measured electrical resistance value of each thickness is linearly extrapolated to zero thickness to determine the electrode contact resistance. It is then subtracted from each measurement. Each corrected resistance value is converted to resistivity by multiplying it by the ratio of the surface area of the electrode to the sample thickness. Conductivity is the inverse of resistivity.

The measurements will be repeated at elevated temperatures. Electrical conductivity at four to five different temperatures will be determined so that the effect of temperature on the relation between conductivity and water content can be established. The temperature of the sample will be kept below the boiling point of water.

Material adjacent to the test samples and the test samples themselves will be used in microprobe analysis to determine mineralogical changes before and after the experiment. This result can provide information on the cation exchange capacity of the minerals. The cation exchange capacity will be used to evaluate the effect of water saturation on the bulk electrical conductivity of tuff (Waxman and Smits, 1968).

\subsubsection{One-Dimensional Dehydration and Imbibition of Matrix}

The rates of one-dimensional dehydration and imbibition can be used along with the moisture retention curve during draining and imbibition to calculate the relative permeability as a function of saturation. The calculation of relative permeability will be discussed in activity plans. An intact sample machined into a cylinder or block will be used for this experiment. At least three samples of each rock type will be tested. $\mathrm{J}-13$ or appropriate water will be used as pore fluid, at the discretion of the scientist in charge. The hydrological properties of the material as specified in Section 6.1, except 
the Klinkenberg coefficient, will be determined.

A cylindrical or block sample of at least $2.5 \mathrm{~cm}$ diameter (or square) and $10 \mathrm{~cm}$ in length will be used in the test. The sample will be instrumented with electrodes and pressure transducers. It will also be jacketed so that no moisture can be transported in or out of the sample except through one end. We will start with a saturated sample. The sample will be heated uniformly and gradually from all sides to encourage dehydration. The temperature in the sample will be maintained below the boiling point of the pore fluid. The dehydration rate will be measured as a function of time by weighing the sample periodically. The drying front will be located using the electrical resistivity measurement. Pore pressure in the sample will be measured using a pressure transducer.

When the sample is dry, water will be placed in contact with the open end and allowed to be imbibed into the sample. The imbibition rate will be determined as a function of time. The distribution of moisture in the sample will be determined, again, using electrical resistivity measurement. Pore pressure will also be measured.

We will also conduct another set of one dimensional imbibition experiments that air is allowed to escape the sample during the imbibition process. Cylindrical samples as described above will be jacketed on the side, leaving both ends exposed. The sample will be equiped with the same monitoring sensors as described above. One end of the samples will be brought in contact with water. The imbibition rate, the moisture distribution, and pore pressure will be measured as a function of time. The result of this imbibition experiment will be compared with the one described above, in which air is not allowed to leave the sample.

\subsubsection{Infiltration of Water in a Fracture}

The speed of infiltration of water in a fracture and the imbibition of water into the matrix from the fracture will be studied. The results will be used for numerical 
model validation. This study will be done at room pressure and temperature. A long sample will be used. The sample may be a circular cylinder or a rectangular column. The hydrological properties of the same material as the test sample as specified in Section 6.1 will be determined before the test.

A sample about $1 \mathrm{~m}$ long with a saw cut along its axis will be used. The aperture of the saw cut will be controlled within a range from about 20 to $100 \mu \mathrm{m}$. The surfaces of the saw cut will be polished flat and smooth to within a typical grain size and cleaned to be free of debris. The sample will be equipped with vapor deposited electrodes on the fracture surfaces, transverse to the main flow direction, to monitor the flow of water in the fracture. The distribution of moisture content in the matrix will be monitored by electrical resistivity tomography, using electrodes on the sample surface.

The experiment will start with a sample of known moisture content. A line source of water will be applied along the fracture at one end of the sample (the upstream end). The water head will be controlled. The water speed in the fracture and the distribution of moisture content in the matrix as a function of time will be determined.

The procedures may be repeated for samples with various degrees of water saturation. In that case, a predetermined amount of water will be added to a dry sample. The added water will be allowed to uniformly redistribute in the sample before the experiment begins.

\subsubsection{One-Dimensional Dehydration and Imbibition in Saw-cut Samples}

The rate of dehydration as a function of time and space in a cylindrical sample with a saw cut along its axis will be determined. When the sample is dry, it will be rehydrated, and the imbibition rate and the moisture distribution in the sample will be determined. The results will be used for model validation. This experiment is similar 
to that described in 6.2.3, except that the sample will contain a saw-cut instead of being intact. The hydrological properties as specified in Section 6.1 of the same material as the sample will be determined before the experiment is started. The information for the matrix part will be measured using a piece of material from the same block as the sample of this experiment. The fracture permeability will be determined on the sample actually being tested in the experiment.

A cylindrical sample of at least $2.5 \mathrm{~cm}$ diameter and $10 \mathrm{~cm}$ length will be used. The sample will have a saw-cut along its axis. The saw-cut surfaces will be prepared as described in Section 6.2.4. The aperture of the saw-cut will be controlled. The sample will be saturated with J-13 water or other appropriate liquid. Electrodes will be mounted on the sample surface. Pore fluid pressure in the matrix near the sealed end of the sample will be measured. The sample will be jacketed so that vapor will not escape except through one end. Drying will occur by heating the sample gradually either from all sides or from one end. The heating rate and maximum temperature will be determined by scoping calculations. Total water content, pore pressure, and vapor flowing out of the sample will be determined as a function of time. Electrical resistance tomography will be used to monitor the distribution of water in the sample as a function of time.

After drying is essentially complete, water will be brought in contact with the open end of the sample. Total water content, pore pressure, and the distribution of water in the sample will be determined as function of time. The imbibition will be either against gravity, with gravity, or perpendicular to gravity. The fracture surfaces and the matrix of the sample will be examined for mineralogical alteration and/or salt deposition, as described in Section 6.2.1. We will also conduct a set of imbibition experiments that air is allowed to escape the sample during imbibition, as described in Section 6.2.3.

\subsubsection{Vapor Condensation in a Fracture}


The amount and distribution of vapor condensing in a fracture at room conditions will be determined. Results will be used for model validation. A cylindrical sample of Topopah Spring tuff or equivalent material with a saw-cut will be used. The sample may be either a circular cylinder or a square column. The hydrological properties as specified in Section 6.1 of the material adjacent to the sample will be determined before the experiment is conducted. These properties of the matrix part of the sample will be measured on a piece of the material from the same block as the sample used in this experiment. The fracture permeability will be measured on the sample actually being tested in the experiment.

A cylindrical sample of at least $2.54 \mathrm{~cm}$ in diameter (or square) and $20 \mathrm{~cm}$ in length will be used in the experiment. The sample will contain a longitudinal saw-cut parallel to its axis. The saw-cut surfaces will be prepared as specified in Section 6.2.4. The saw-cut aperture will be controlled. Electrodes will be vapor deposited on the sample and on the saw-cut. Steam or moist air will be injected into the saw cut. The entire sample will be kept under the dew point. Total water content will be measured as a function of time. Electrical resistivity measurements will be used to monitor the position of condensed water on the saw-cut surfaces. Electrical resistance tomography will be used to monitor the water distribution in the sample as a function of time. The same procedures will be repeated on samples with various degrees of initial water saturation.

\subsubsection{Three-Dimensional Imbibition}

The movement of a water front from a three-dimensional imbibition process in a tuff sample or equivalent material will be determined. Results will be used to compare with result from the one-dimensional imbibition experiment described in Section 6.2.3 and for model validation. The hydrological properties as specified in Section 6.1 of the material adjacent to the sample will be determined before the experiment. These properties will be measured using several pieces of material from the same block as 
the sample used in this experiment, so that the block scale variability of matrix properties can be determined. An intact sample of at least $7.5 \mathrm{~cm}$ in diameter and $10 \mathrm{~cm}$ in length will be used. Electrodes will be vapor deposited on the sample surface to facilitate the use of electrical resistance tomography to monitor the distribution of moisture in the sample.

A dry sample will be used. The sample will be submerged in either water or water vapor at room temperature and pressure. The total imbibition rate will be determined by either measuring the total weight change of the sample when it is in water, or measuring the volume change of the imbibing water. Electrical resistivity tomography will be used to locate the imbibition front of water as a function of time. The procedures will be repeated for samples with various degrees of initial moisture content. 


\subsection{Application of Results}

The laboratory determined hydrological properties of Topopah Spring tuff, as described in Section 6.1, will provide input data for numerical model calculations that will predict the hydrological processes in the near-field environment of a nuclear waste repository. The model validation experiments, as described in Section 6.2, will provide validation and calibration of the code and concepts that will be used in the model calculations. Fluid flow features in the near-field environment will be defined so that the radionuclide release and transport models can be developed, and the Waste Package Performance Assessment can be accomplished. The results of these studies will be used in waste package design in the area of waste package interactions with the emplacement environment.

The information derived from these activities will be used in addressing the following specific Information Needs (IN) and corresponding descriptions in the Site Characterization Plan (SCP):

SCP 8.3.5.9.3 (IN 1.4.3): Scenarios and models needed to predict the rate of degradation of the container material.

SCP 8.3.5.9.4 (IN 1.4.4): Estimates of the rates and mechanisms of container degradation in the repository environment for anticipated and unanticipated processes and events, and calculation of the failure rate of the container as a function of time.

SCP 8.3.5.10.3 (IN 1.5.3): Scenarios and models needed to predict the rate of radionuclide release from the waste package and engineered barrier system.

SCP 8.3.5.10.4 (IN 1.5.4): Determination of the release rates of radionuclides from the waste package and engineered barrier system for anticipated and unanticipated events. 
SCP 7.2.1.3.1 (IN 1.10.1): Design information needed to comply with postclosure criteria from $10 \mathrm{CFR}$ 60.135(a) for consideration of the interactions between the waste package and its environment.

SCP 7.4.5.4.5: Waste package environment model to evaluate the flow of water, steam, and air that can affect the waste package barriers and the waste form. 


\subsection{Acknowledgements}

C. Cassidy edited this manuscript. This work is supported by the Yucca Mountain Site Characterization Project at Lawrence Livermore National Laboratory. Reviews by J. Blink and D. Chesnut greatly improve this manuscript. 


\subsection{References}

Buscheck, T.A., J.J. Nitao and D.A. Chesnut, 1991, "The Impact of Episodic Nonequilibrium Fracture-Matrix Flow on Geological Repository Performance", in Proceedings American Nuclear Society Topical Meeting on Nuclear Waste Packaging (Focus 91), Las Vegas, NV, Sept. 30 - Oct. 2, 1991. Also UCRLJC-106759, Lawrence LIvermore National Laboratory, Livermore, CA 1991. NNA.911231.0023

Buscheck, T. A. and J. J. Nitao, 1991, "Modeling Hydrothermal Flow in Variably Saturated, Fractured, Welded Tuff During the Prototype Engineered Barrier System Field Test of the Yucca Mountain Project",Lawrence Livermore National Laboratory UCRL-JC-106521, Livermore, CA. NNA.911212.0238

Daily, W. D. and W. Lin, 1985,"Laboratory-determined Transport Properties of Berea Sandstone", Geophysics, Vol. 50, 775-784. (Readily Available)

Daily, W., W. Lin, and T. Buscheck, 1987, "Hydrological Properties of Topopah Spring Tuff: Laboratory Measurements", J. Geophys. Res., Vol. 92, No. B8, 7854-7864. NNA.900123.0064

Daily, W. and W. Lin, 1991, "Laboratory Determined Suction Potential of Topopah Spring Tuff at High Temperatures", in High Level Radioactive Waste Management, Proceedings of the Second Annual International Conference, Las Vegas, Nevada, April 28 - May 3, 1991, ANS, La Grange Park, IL, pp. 583588. NNA.910304.0097

Flint, L. E., M. S. Nash, and A. L. Flint, 1992, "Rapid Determination of Moisture Retention Curves Using a Chilled-Mirror Psychrometer", EOS Transaction, American Geophysical Union, Vol. 73, No. 43, p223. (Readily Available) 
Heid, J. G., J. J. McMahon, R. F. Nielson, and S. T. Yuster, 1950, "Study of the Permeability of Rocks to Homogeneous Fluids", API Drill. Prod. Practice, pp. 230-246. NNA.931005.0002

Klavetter, E. A. and R. R. Peters, 1987, Fluid Flow in a Fractured Rock Mass, SAND85-0855, Sandia National Laboratories, Albuquerque, NM. HQS.880517.1786

Lee, K. and J. Ueng, 1991, "Permeability Tests", Chapter 3 of Prototype Engineered Barrier System Field Test (PEBSFT) Final Report, A. Ramirez, Ed., UCRL-ID-106159, LLNL, pp. 40-50. NNA.910711.0047

Lin, W., 1991, "Variation of Permeability with Temperature in Fractured Topopah Spring Tuff Samples", in High Level Radioactive Waste Management, Proceedings of the Second Annual International Conference, Las Vegas, Nevada, April 28 - May 3, 1991, ANS, La Grange Park, IL, pp. 988-993. NNA.9105223.0105

Lin, W., 1992, "Hydrologic Properties", Chapter 2 of Preliminary Near-Field Environment Report Volume II: Scientific Overview of Near-Field Environment and Phenomena, D. Wilder, Sci. Ed., Lawrence Livermore National Laboratory UCRL-LR-107476, p. 2-5. NNA.920501.0002

Lin, W. and W. Daily, 1984, Transport Properties of Topopah Spring Tuff, UCRL-53602, LLNL, Livermore, CA. NNA.891026.0025

Lin, W. and W. Daily, 1989, "Laboratory Study of Fracture Healing in Topopah Spring Tuff - Implications for Near Field Hydrology", Proceedings of the Topical Meeting on Nuclear Waste Isolation in the Unsaturated Zone, Focus '89, American Nuclear Society, La Grange Park, IL. NNA.900711.0241 
Lin, W. and W. Daily, 1990, "Hydrological Properties of Topopah Spring Tuff under a Thermal Gradient--Laboratory Results", Int. J. Rock Mech. Min. Sci. \& Geomech. Abstr. Vol. 27, No. 5, 373-385. (Readily Available)

Montazer, P. and W. E. Wilson, 1984, "Conceptual Hydrological Model of Flow in the Unsaturated Zone, Yucca Mountain, Nevada", USGS-84-4345 Water Resources Investigative Report, U. S. Geol. Survey, Denver, CO. NNA.890237.0051

Montazer, P., E. P. Weeks, F. Thomas, S. P. Yarp, and P. E. Hofrichter, 1985, "Monitoring the Water Zone in Fractured Tuff, Yucca Mountain, Nevada", National Water Well Association Symposium, Denver, CO., November 19-21. NNA.900924.0023

Moore, D.E., C. Morrow, and J. Byerlee, 1986, " High-temperature Permeability and Groundwater Chemistry of Some Nevada Test Site Tuffs", J. Geophys. Res. 91(B2). pp. 2163-2171. (Readily Available)

Nimick, F. G. and B. M. Schwartz, 1987, Bulk, Thermal and Mechanical Properties of the Topopah Spring Member of the Paintbrush Tuff, Yucca Mountain, Nevada. SAND85-0762, Sandia National Laboratories, Albuquerque, NM. NNA.870723.0015

Ortiz, T. J., R. L. Williams, F. B. Nimick, B. C. Whittes, and D. L. South, 1985, A Three-Dimensional Model of Reference Thermal Mechanical and Hydrological Stratigraphy at Yucca Mountain, South Nevada. SAND84-1076, Sandia National Laboratories, Albuquerque, NM. NNA.890315.0013

Preuss, K., Y. W. Tsang, and J. S. Y. Wang, 1984, Numerical Studies of Fluid and Heat Flow near High Level Waste Packages Emplaced in Partially 
Saturated Fractured Tuff. LBL-18552, LBL, Berkeley, CA. HQS.880517.1705

Reda, D. C., 1987, "Slip-Flow Experiments in Welded Tuff: The Knudsen Diffusion Problem", in Coupled Processes Associated with Nuclear Waste Repositories, C. Tsang Ed., Academic Press, New York, NY, pp. 485-493. NNA.931005.0003

RIB, 1992, Reference Information Base, Yucca Mountain Site Characterization Project, \#YMP/93-02 (Revision 2), pp. 1.2.3. NNA.930517.0053

Scott, R. B., R. W. Spengler, S. Diehl, A. R. Lappin, and M. P. Chornack, 1983, "Geological Character of Tuff in the Unsaturated Zone at Yucca Mountain, South Nevada", in J. W. Mercer, P. S. C. Rad and I. W. Marim, Eds., Role of the Unsaturated Zone in Radioactive and Hazardous Waste Disposal (Ann Arbor Science, Ann Arbor, MI), p. 289. HQS.880517.1446

Wang, J. S. Y. and T. N. Narasimhan, 1985, Hydrologic Mechanisms Governing Fluid Flow in Partially Saturated, Fractured, Porous Tuff at Yucca Mountain. SAND84-7202, Sandia National Laboratories, Albuquerque, NM. NNA.870407.0209

Waxman, M. H. and L. J. M. Smits, 1968, "Electrical Conductivities in OilBearing Shaly Sands", Soc. Petrl. Eng. J., June, 1968, pp. 107-122. NNA.931005.0004 


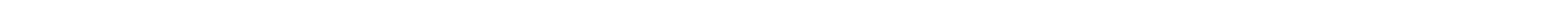


